\title{
Lay health workers and HIV programmes: Implications for health systems
}

\author{
H. Schneider ${ }^{a}$ and U. Lehmann ${ }^{b}$ \\ a Centre for Infectious Disease Epidemiology and Research, School of Public Health \& Family Medicine, \\ University of Cape Town, Anzio Road, Observatory, Cape Town 7925, South Africa; ${ }^{b}$ School of Public \\ Health, University of the Western Cape, Cape Town, South Africa
}

\begin{abstract}
One of the consequences of massive investment in antiretroviral access and other AIDS programmes has been the rapid emergence of large numbers of lay workers in the health systems of developing countries. In South Africa, government estimates are 65,000, mostly HIV/TB care-related lay workers contribute their labour in the public health sector, outnumbering the main front-line primary health care providers and professional nurses. The phenomenon has grown organically and incrementally, playing a wide variety of care-giving, support and advocacy roles. Using South Africa as a case, this paper discusses the different forms, traditions and contradictory orientations taken by lay health work and the system-wide effects of a large lay worker presence. As pressures to regularise and formalise the status of lay health workers grow, important questions are raised as to their place in health systems, and more broadly what they represent as a new intermediary layer between state and citizen. It argues for a research agenda that seeks to better characterise types of lay involvement in the health system, particularly in an era of antiretroviral therapy, and which takes a wider perspective on the meanings of this recent re-emergence of an old concept in health systems heavily affected by HIV/AIDS.
\end{abstract}

Keywords: lay health workers; home-based care; health systems; HIV

\section{Introduction}

The growth in global health funding has made possible scaled up access to antiretroviral therapy (ART) in poor countries across the world, not only dramatically altering the lives of many people living with HIV, but also changing the way in which health care is organised and delivered. There now is increasing recognition of the need to examine the broader system impacts of these massive new investments in disease-specific programmes and whether they do achieve their stated goals of "health system strengthening" (WHO Maximizing Positive Synergies Collaborative Group, 2009). In many low-income countries of sub-Saharan Africa, funding for HIV through initiatives such as the Global Fund for HIV, tuberculosis (TB), Malaria and the President's Emergency Fund for AIDS Relief (PEPFAR) dwarfs spending on the rest of the health system (Marchal, Cavall, \& Kegels, 2009) and has the potential to 
fundamentally alter the nature of provision, organisation, actors and relationships in the health system.

In South Africa, funding from global health initiatives is less dominant than in other Sub Saharan African countries, but still very significant: in 2008/2009, donor funds contributed roughly $5 \%$ of public health spending in South Africa (Blecher, Day, Dove, \& Cairns, 2009). This is significant for a middle-income country, especially since much of it is allocated to HIV/TB programmes. Furthermore, since the advent of an antiretroviral access programme in South Africa in 2004, public spending on HIV programmes has increased substantially annually in real terms by $21.6 \%$ (Blecher et al., 2009).

One of the key system-wide effects of large new investments in the HIV response in South Africa and elsewhere has been the growth of lay health worker1 involvement in the health system and related to this, the emergence of a complex and diverse new "economy of care" (Ogden, Esim, \& Grown, 2006) at the boundaries of the formal health and social welfare systems. In a context of general health worker shortages, community members have taken on care roles where care is not available; community-based organisations have sprung up to advocate and support people living with HIV/AIDS (PWA) through newcadres of counsellors and peer supporters; and non-governmental organisations (NGOs) have formed care and support networks which make use of different cadres of lay personnel. This mobilisation of non-professionals has catered for new forms of service provision within health facilities, but has also led to a shift of care from a fragile formal health system to households and communities. "Community-based" services are nowan established and growing part of district health system budgets (Blecher et al., 2009) and there is now virtually no primary health care clinic in South Africa without its complement of lay workers, either facility-based or providing home-based care within its catchment area. Health care, most specifically TB and HIV care, would simply be unimaginable without the services of an army of lay health workers. Activities such as counselling and home-based care have become routine functions within the health system and the exclusive preserve of lay health workers, who increasingly occupy a front-line service provision role. Collectively, lay workers represent a new mediating layer between the formal health system and citizens.

Although the South African government has become the main driver and funder of lay health workers, they remain outside of the formal health system and are employed and managed through nongovernmental intermediaries. This has resulted in an unregulated and uncoordinated proliferation of cadres with different orientations and skills and playing diverse roles (Friedman, 2005). Approaches to the governance, management and remuneration of lay health workers vary considerably across provinces and localities (Lehmann, Matwa, Schneider, \& Colvin, 2009). This fragmentation and the precarious location on the margins of the formal health system have created a host of problems, including the failure to recognise lay workers as health system employees and ensure appropriate systems of remuneration and employment benefits; poor disbursement of funds to employing NGOs; poor integration into primary health care teams; problematic relationships with ealth professionals and facilities; and inadequate training, support,

\section{https://repository.uwc.ac.za/}


supervision and career pathing (Samson, 2008; Schneider, Hlophe, \& van Rensburg, 2008). Increasingly, there are demands from civil society and policy initiatives by various government departments to address and resolve these issues.

The deployment of lay workers and the problems associated with them are not new phenomena, in South Africa or internationally, but have been around for at least 50 years (Lehmann \& Sanders, 2007). There have been innumerable experiences throughout the world with programmes ranging from large-scale national programmes to small-scale community-based initiatives. In the years following the 1978 Alma Ata Declaration on Primary Health Care, community health workers ( $\mathrm{CHW}$ ) were promoted and became a part of many developing country health systems, but fell out of favour, largely due to unrealistic expectations and lack of adequate planning, management and reliable funding (Gilson et al., 1989; Walt, 1990). While early programmes emphasised the role of CHWs not only as health care providers, but also as advocates for the community and agents of social change, today's programmes emphasise their health service delivery and community management function (Lehmann \& Sanders, 2007).

The current wave of enthusiasm for lay workers, especially in sub-Saharan Africa, 2 is in response to the need for a readily available and inexpensive workforce that can perform new tasks associated with disease-specific initiatives. Much of the debate around lay workers is thus centred on the access gains and technical feasibility of using them to provide specific services such as TB care, HIV testing or ART-related support. Research has tended to focus on the safety and efficacy of deploying lay workers for particular problems (Lewin et al., 2005) or the possibilities of "task shifting" (WHO/UNAIDS/PEPFAR, 2008) important issues in their own right. However, these debates make little reference to the social and systems impact of the presence of new providers and services on such a wide scale, or to their role and location as mediators between the formal health services and communities.

Using South Africa as a case, this paper discusses the different forms, traditions and sometimes contradictory orientations taken by lay health work, the system-wide effects of a large lay worker presence, and the difficulties of imposing coherence and uniformity, through policy, on such a field. It argues for research that seeks to better characterise types of lay involvement in the health system, particularly in an era of ART, and which takes a wider perspective on the meanings of this recent re-emergence of an old concept within developing country health systems.

\section{Methods}

The paper's primary purpose is to contextualise current debates on lay work from a health system perspective. It draws on insights gained from projects in which the authors participated over the last few years. These included:

\section{https://repository.uwc.ac.za/}


- A national mapping exercise of lay health workers linked to public sector initiatives, conducted in late 2008 (Lehmann et al., 2009).

- A longitudinal study of changing lay health worker experiences in the Free State Province (Hlophe \& Schneider, 2007; Schneider et al., 2008).

- A case study of lay worker programme practices in a rural Eastern Cape district (Lehmann \& Matwa, 2008).

In addition, the paper makes use of a considerable body of published work grey and indexed on different types of lay workers in the South African setting, including "directly observed therapy, short course (DOTS) supporters" for TB, lay counsellors, home-based carers and generalist CHWs.

The paper begins by providing a profile of growing lay health worker presence in the South African health system; it considers in more detail the different types of lay health workers and their orientations. The paper then discusses possible systemic impacts of lay work and policy responses to this, and concludes by proposing a health systemrelevant research agenda on lay health workers.

\section{Profile of lay health workers in the South African health system}

In a field characterised not only by rapid change, but also by blurred boundaries between household caring, volunteerism and regular labour, quantifying the lay health worker contribution to the health system is not easy. However, the evidence does show:

1. A rapid growth in numbers of lay workers linked to South Africa's public health system from 2000 onwards.

2. A numerically significant presence relative to professional health workers.

3. The highly gendered profile of lay workers.

Prior to the advent of HIV in South Africa there were a number of small scale, generalist CHW programmes across the country, employing a limited number of workers, estimated at around 5600 (Cruse, 1997). Interestingly, several of these models were anchored within the formal health system. In Limpopo Province, for example, 'care-group facilitators", employed through a local hospital, mobilised a massive volunteer network of "care groups" (Cruse, 1997). Despite proposals for scaling up CHWs by these programmes, however, they received little moral or financial support from the newly elected post apartheid government, and many subsequently folded (Friedman, 2005). From the mid to late 1990s, influenced by models in other parts of south and eastern Africa, non-governmental and faith-based "home-based care" projects began to emerge across the country, using lay workers to provide palliative care to HIV-infected people and support for their orphaned children. In parallel developments, lay counsellors started being trained to work in AIDS Training, Information and Counselling

\section{https://repository.uwc.ac.za/}


Centres in a number of municipalities, and projects experimenting with the idea of community "DOTS3 supporters" for TB care were established.

These various initiatives provided the precedents and templates for a new generation of lay health workers in South Africa, and in 2000, national government began allocating ringfenced grants to expand "home and community-based care" (HCBC) and "voluntary counselling and testing (VCT)" in heath facilities (Hickey \& Whelan, 2001). From then on there was a rapid growth in state supported non-profit organisations (NPOs) employing "community care givers (CCG)" in both health and welfare sectors. Titles, training and functions corresponding to specific services VCT counsellors, child care workers, homebased carers, DOTS supporters, ART adherence counsellors to name a few, were introduced. In 2002, a national audit counted a total of 31,565 carers in the two sectors (Department of Health \& Department of Social Development [DOH\& DSD], 2003); by 2004 the figure had gone up to 40,000 (DOH, 2004), and rising to 65,000 in 2006 (DOH, 2006). In 2007/2008, an estimated 65,000 “work opportunities" were reportedly provided through NPOs in the health sector alone (DOH/DSD, 2009).

A mapping exercise conducted at the end of 2008 sought to establish more precisely the numbers and roles of lay workers employed on a regular basis in the public health system (Lehmann et al., 2009). This inventory identified a total of 1636 NPOs funded by contracts with provincial health departments, employing close to 40,00o lay workers (Table 1). This excludes many, difficult to quantify, workers in "unlinked" initiatives funded through a sizeable donor presence in HIV/AIDS and TB or volunteers in small community-based organisations. To place the numbers in perspective, in 2008, the public health sector employed 48,00o professional nurses and 10,700 medical practitioners (Day \& Gray, 2008), only a proportion of who work in the primary health care system. Lay workers are thus now as numerically significant, if not more so, than other categories of health professionals.

While the majority of lay workers are categorised as specialist HIV/TB workers, there is a trend towards embracing more generalist notions of CHWs, that can assume a number of functions beyond HIV/TB (Table 1) such as community integrated management of childhood illness (IMCI),chronic non-communicable disease support groups and rehabilitation. This gradual widening of competencies was evident in a longitudinal study of lay workers in 16 localities conducted in one province, Free State between 2004 and 2007 (Hlophe \& Schneider, 2007). At baseline, the majority (75\%) of lay workers had separate identities as "lay counsellor", "home-based carer" or "DOTS supporter". By 2007, the reverse was true: $87 \%$ had received training, and regarded themselves, as a combination of all three. In this study, 93\% of the lay workers were female, reflecting patterns elsewhere in the country (Akintola, 2006; Friedman et al., 2007).

Table 1. Non-profit organisations (NPOs) and lay health workers contracted by provincial health departments, 2008.

\section{https://repository.uwc.ac.za/}




\begin{tabular}{lllll} 
& NPOs & Percentage & Lay workers & Percentage \\
\cline { 2 - 5 } HIV/TB workers & 1122 & 68.6 & 21,732 & 56.9 \\
Generalist CHW & 302 & 18.5 & 12,325 & 32.3 \\
Other, e.g., mental health workers & 212 & 13.0 & 4112 & 10.8 \\
Total & 1636 & 100 & 38,169 & 100.0
\end{tabular}

Source: Lehmann et al. (2009).

\section{Origins and forms of lay work}

As alluded to, lay workers form a diverse mix of histories, orientations and purposes, despite the blending of forms and their shared status outside of the formal health system.

Home-based care was introduced to promote caregiving in the home, with support from home-based carers trained in basic palliative care. As stated in DOH (2001, p. 2) guidelines: "As more people become ill, many will not be able to stay in hospitals, hospices or other institutions for care. It is also recognised that South Africa has limited health care resources. Situations will arise where, even if hospital or other institutional care may be the best response to an individual's condition, it may not be available to him/her." Home-based care aimed to shift burdens of care, particularly terminal care from the formal health system, to semi-formal agents of care in private, nongovernmental organisations and to house holds. With a few notable exceptions (Uys, 2002), the practice of home-based care implied delegating responsibility for death and dying to household members, generally women, who had to manage the difficult and deeply stressful process with little external support (Akintola,2006; Hunter, 2006). Couched in a language of a seamless "continuum of care" (WHO, 2002) between health system, community and home, and drawing on "communitarian" ideas of reciprocity and caring in African culture, it's more "profane" (Marais, 2005) or real role was to legitimate the widespread practice of turning people with end stage AIDS away from overburdened health facilities.

Lay counsellor training in South Africa has its roots in a somewhat different tradition. It emerged from a professional base of psychology in counselling and testing centres. As described by Rohleder and Swartz (2005, p. 398), "Counsellors are trained in a client-centred approach to counseling. . . [which] emphasizes the centrality of the counsellor-counsellee relationship and aims to develop counsellors who respect the position of those they counsel without imposing their own values." In practice, "a mixture of client-centred and more directive, health-advising counselling techniques tend to be used". Lay counsellors form the basis of the HIV VCT service, and since 2004 have provided treatment preparation and support for people enrolled in the ART programme. The approach to "adherence counselling", adopted in the ART programme was also influenced by models such as that of the Me' dicins-Sans-Frontie' res/Treatment Action Campaign (MSF/TAC)-supported Khayelitsha programme that drewon notions of rights from the AIDS social movement 
right to treatment and care, social support and information (Schneider \& Coetzee, 2003). This tradition has favoured the enrolment of "expert patients", people living with HIV or TB who have successfully negotiated care, as adherence counsellors. The management of adherence in the ART programme thus evolved in a manner distinct from that of the TB programme (see below). It emphasised building patient knowledge and autonomy through "treatment preparation", and the mobilisation of social networks through support groups and nomination of treatment supporters.

While ART adherence counselling aims to achieve an internalised responsibility for adherence to ART, "directly observed therapy (DOT)" of TB, as the name implies, is a form of external supervision. Its roots in a public health tradition of patient and programme monitoring is succinctly captured by Wilkinson, Davies, and Connolly (1996) who write:

"The patient visits his or her supervisor twice weekly and ingests the treatment under direct observation; the visit is recorded by the supervisor who holds the patient's treatment card. A field worker visits each supervisor monthly to collect data on absconders, deaths, and patients who have completed treatment." The practice of DOT has been questioned as not evidence-based, creating barriers to access by forcing patients to travel to DOT supervisors to get treatment, and undermining patient autonomy (Porter \& Ogden, 1997; Volmink \& Garner, 2007).

Although the name DOTS remains firmly institutionalised, its practice has evolved into a less authoritarian concept involving choice and support for patients (see for example, Clarke, Dick, Zwarenstein, Lombard, \& Diwan, 2005; Maher, 2003; Marq, Theobald, Dick, \& Dembele, 2003).

In contrast to other types of lay work, counselling is a predominantly facility-based activity in South Africa. While home-based care has become more general in focus, HIV counselling has tended to remain a core specialised function in the health system, and lay counsellors constitute roughly $10 \%$ of the total of lay workers (Lehmann et al., 2009). Lay counsellors are often paid more (Lehmann et al., 2009), and may express a higher degree of professional efficacy than home-based carers (Schneider et al., 2008), despite still experiencing a lack of recognition from other health professionals (Rohleder \& Swartz, 2005).

These various forms of lay work are summarised in Table 2 below. It is clear that they embody different and at times contradictory notions of access and entitlement, as well as expectations of patients, and ultimately, meanings of "therapeutic citizenship" (Nguyen, 2007). HCBC signals a limit to claims on the health system, even in its more generalist contemporary versions, and has lost much of the ideas of community mobilisation associated with earlier generations of CHW programmes. Antiretroviral (and increasingly TB) programmes and the agents associated with them, on the other hand, represent a paradigm shift back towards a rights-based approach of expanding entitlements through the formal health system and increased investment in primary health care programmes.

\section{https://repository.uwc.ac.za/}




\section{Policy}

Although initially premised on a model of voluntary contribution, a growing dependence on the labour of lay health workers for the every day functioning of the health system led to a series of shifts in the policy environment. Policy initiatives on lay workers have been launched from several components of government, including an "Expanded Public Works Programme" and the DSD and DOH. In 2003, the DOH released a CHW framework proposing the institution of "stipended" volunteers and setting a minimum stipend level of R100o per month (DOH, 2003). A more recent version, referred to as the "CCG policy framework" (now in its fourth draft), goes one step further and seeks to recognise lay workers as regular employees, subject to provisions of labour law (DOH/DSD, 2009). One estimate suggests that full funding of employees in community-based services would require an increase of $1.3 \%$ to current public health expenditure (Blecher et al., 2009). In addition, it seeks to align diverse practices towards lay workers in provincial governments by creating one overarching concept of CCGs that incorporates all lay worker cadres, provided with a uniform and relatively low level of training as generalists, and united by their common mode of state engagement through NPO intermediaries. While still in draft form, and one of several policy proposals, the draft CCG policy framework is indicative of approaches to the future of lay workers in at least part of the state. That is, the desire to sharpen the distinction between "lay" and other work, and consolidate the community "care economy" outside of the formal health system. This appears at odds with an HIV programme that has as a core objective improving access to antiretroviral treatment and other care services within the formal health system.

Table 2. The origins, purpose and values underlying different forms of HIV/TB-related lay work in South Africa.

\begin{tabular}{llll}
\hline & Origins & Purpose & Values \\
& & & \\
Home-based care & Volunteering faith-based, hospice & Care in the home & Dehospitalisation, self-reliance \\
Lay counselling & Psychology/social work & Testing, psycho-social & Client-centred, autonomy \\
& & support, advice & \\
ART adherence counselling Human rights, PWA & Adherence/retention & Empowerment, self management \\
& Movements & in care & \\
Advocacy/activism & PWA movements & Increase access, mediate & Human rights, expert patients \\
& & care, mutual support & \\
DOTSa support & Public health & Adherence & Patient supervision \\
& & & \\
\hline
\end{tabular}

Note: PWA, people living with HIV/AIDS; DOTS, directly observed therapy, short course.

\section{https://repository.uwc.ac.za/}


Implications for health systems The state's attitude to lay health workers is thus ambiguous. On the one hand, by locating them firmly outside of the boundaries of the formal health system it perpetuates a state of marginalisation and re-enforces the divide between "home community-based care" and other forms of care provision. Despite their centrality to the functioning of the primary health care system, lay workers continue to be excluded from health sector human resource and service planning frameworks; there is no standardised training and few opportunities for career pathing (Lehmann, 2008) and little obligation to define roles and normalise relationships with other health professionals, for the most part still highly precarious (Rohleder \& Swartz, 2005; Schneider et al., 2008); the funding of NPOs employing lay workers is still heavily donor dependent (Lehmann et al., 2009) and external contracts with small suppliers (including NPOs) are the first to suffer when provincial governments have cash flow problem s. Lay health workers thus remain a low status, flexible and semi-formal workforce on the margins of the health system, that can expand and contract easily as circumstances change.

Collectively, the growth of lay work represents an informalisation of essential health care delivery in South Africa's public health system, consequent on reduced state expenditure and the devastating impact of the HIV epidemic. As Marais (2005, p. 65) suggests: "The ascendancy of home- and community-based care needs to be understood in a wider historical context. Generally, the ethic of care as a household and community responsibility its veritable 'privatization', consigning it to the sphere of the home has coincided with the increasingly implacable subordination of social life to the rules of the market. Many of the assumptions and injunctions surrounding home-based care (and by extension also coping) dogma fit snugly with neoliberal discourse".

On the other hand, the state's acknowledgement of its responsibility to support the care economy, even if indirectly, suggests recognition of the centrality of lay work to the formal health system's functioning. In doing so, it opens the space for further claims on part of lay workers, who believe themselves to be employed by the state (Schneider et al., 2008), if not state employees. Pressures for greater incorporation into the formal sector will thus remain. There is also a limit to which national government, through its policy directives, can engineer boundaries between sectors and shape perceptions of rights and entitlements, particular in the context of a constitution that promises the progressive realisation of social and economic rights, an active civil society, the fiscal space for some degree of manoeuvre with regard to social policy, and decentralised decision-making in a federal political system.

If the forms and training of lay workers outlined above have their roots in different ideological traditions and expectations, the practice of lay work tends to be complex, fluid and heterogenous, defying attempts to develop a one-size-fits-all package of services or mode

\section{https://repository.uwc.ac.za/}


of regulation (Daniels, Van Zyl, Clarke, Dick, \& Johansson, 2005; Henderson, 2008; Uys, 2002). This is true in South Africa as much as elsewhere in the world. In the plural health care environment of Bangladesh, for example, Standing and Chowdhury (2008, pp.

2104 2105) identified four models of community-based health agents: (1) a generic agent associated with a reputable supervisory agency; (2) a specialist cadre working with particular health conditions; (3) an expert advocate; and (4) a mobiliser or facilitator who can mediate between users and health markets.

The ability to be a successful home and community- based carer, in fact, is partly premised on moving beyond a stereotypical caring function and possessing sufficient "systems knowledge" and moral authority to broker access to services such as health care or social grants. There is also anecdotal evidence of the role of lay workers, individually or in collectives extracting greater accountability from local health services. For example, in her fine ethnographic study of a rural area in Kwazulu-Natal, Henderson (2008) describes the skilled actions of a carer in exposing and forcing the resignation of a nurse illegally selling drugs to the community. It is through such actions that lay workers may reclaim their roles as advocates and mobilisers for communities. The answer to growing informalisation is thus not necessarily wholesale incorporation into the formal health system.

\section{Conclusions}

Lay workers have re-emerged as significant phenomenon in health systems over the last decade, largely in response to newfund ing for disease specific programmes and in a context of health worker shortages. They have become essential players in the provision of health care and form part of a broader mobilisation of community and non-governmental participation in the health system, precipitated in sub-Saharan Africa by the HIV epidemic.

The overall health systems impact of this organic and highly plural development is not easy to determine, let alone regulate or shape. However, the emergence of lay workers in South Africa does offer opportunities for improved access and quality of care. Harnessing this potential requires recognising their role as integral to the formal health system and as more complex than a one-way delegation of tasks that this system no longer perceives to be its responsibility. If broader roles are accepted, a more formalised lay health worker infrastructure may lay the ground for newnegoti ated orders with local health services and a strengthening of primary health care. In addition, the diversity of forms and approaches to governance at sub-national level cannot be wished away in the short term. National policy initiatives seeking to create coherence by establishing one approach to lay work and flattening difference may have the unintended consequence of raising expectations without addressing underlying problems.

Much of the discussion on lay work in South Africa is occurring in the dark. A better understanding of this complex and rapidly changing phenomenon is urgently needed. Observational and intervention research on the safety, efficacy and cost effectiveness of lay

\section{https://repository.uwc.ac.za/}


workers in taking on new "taskshifted" roles, the limits to which lay workers can assume multiple roles and still perform adequately, requisite training and support structures, and the balance between generalist and specialist roles, are all important. There is also a need for health services research to better understand the multiple forms and entry points into lay and professional health work and ways of articulating them through both differentiated and permeable career pathways.

However, if appropriate policy is to be developed, a broader systemic view of lay work and the care economy is also required, through research that takes a social and institutional perspective on lay health workers and their roles at the interface between formal health services and civil society. The growth of lay work has created new roles, interests and power relations within the health system. Little is known of this new"industry", its changing forms and organisation, capabilities, networks and orientations. These have to be understood from multiple perspectives, including those of users and their households, lay workers, nongovernmental and community-based organisations, professional providers and the health system as a social institution.

\section{Notes}

1. Lewin et al. (2005) define lay workers as "any health worker carrying out functions related to health care delivery; trained in some way in the context of the intervention; and having no formal professional or paraprofessional certificated or degreed tertiary education." The use of the term "lay health worker" in paper is deliberate and is used to denote their structural position as the opposite of "professional" health workers.

2. This situation is somewhat different to that of Latin America and Asia where generalist CHW programmes remain important components of country health systems (Rohde et al., 2008).

3. DOTS stands for "directly observed therapy, short course", the World Health Organization's model of TB care, implemented in South Africa from the mid-199os. 


\section{References}

Akintola, O. (2006). Gendered home-based care in South Africa: More trouble for the troubled. African Journal of AIDS Research, 5(3), 237247.

Blecher, M.S., Day, C., Dove, S., \& Cairns, R. (2009). Primary health care financing in the public sector. In P. Barron \& J. Roma-Reardon (Eds.), South African health review 2008 (pp. 179 194). Durban: Health System Trust.

Clarke, M., Dick, J., Zwarenstein, M., Lombard, C.J., \& Diwan, V.K. (2005). Lay health worker intervention with choice of DOT superior to standard TB care for farm dwellers in South Africa: A cluster randomised control trial. International Journal of Tuberculosis and Lung Disease, 9(6), 673679.

Cruse, D. (1997). Community health workers in South Africa: Information for provincial policy makers. Durban: Health Systems Trust.

Daniels, K., Van Zyl, H., Clarke, M., Dick, J., \& Johansson, E. (2005). Ear to the ground: Listening to farm dwellers talk about the experience of becoming lay health workers. Health Policy, 73, 92103.

Day, C., \& Gray, A. (2008). Health indicators. In P. Barron \& J. Roma-Reardon (Eds.), South African health review 2008 (239 396). Durban: Health System Trust.

Department of Health (2001). National guidelines on homebased care and community-based care. Pretoria: Author.

Department of Health (2003). Community health workers policy framework. Pretoria: Author.

Department of Health (2004). Speech by Minister of Health, Dr Manto Tshabalala-Msimang, at the launch of the community health worker programme, 26 Feb 2004.

Department of Health (2006, July 7). Social sector cluster media briefing. Pretoria: Author. Retrieved September 4, 2009, from http://www.doh.gov.za/docs/pr/2006

Department of Health, \& Department of Social Development (2003). Appraisal of home community based care projects in South Africa 2002-2003. Pretoria: DSD.

Department of Health/Department of Social Development (2009). Community care giver policy framework for home community based care. Draft 4.0. Pretoria: Department of Health.

Friedman, I. (2005). Community health workers and community care-givers: Towards a model of unified practice. In P. Ijumba \& P. Barron (Eds.), South African health review 2005 (176 189). Durban: Health Systems Trust.

\section{https://repository.uwc.ac.za/}


Friedman, I., Ramalepe, M., Matjis, F., Bhengu, L., Lloyd, B., Mafuleka, A., et al. (2007). Moving towards best practice: Documenting and learning from existing community health/care worker programmes. Durban: Health Systems Trust.

Gilson, L., Walt, G., Heggenhougen, K., Owuor-Omondi, L., Perera, M., Ross, D., et al. (1989). National community health worker programmes: How can they be strengthened? Journal of Public Health Policy, 10(4), 518-532.

Henderson, P. (2008). 'Touching my bones': AIDS, intimacy and care in rural KwaZuluNatal. Unpublished manuscript.

Hickey, A., \& Whelan, P. (2001). HIV/AIDS and budget 2001. Budget Brief no. 62. IDASA Budget Information Service. Retrieved September 4, 2009, from www.idasa.org.za/bis

Hlophe, H., \& Schneider, H. (2007, October). Community health workers in the free state: Integral members of the primary health care system? Paper presented to the Roundtable Conference: Health Systems Strengthening and ART, University of the Free State, Bloemfontein, South Africa.

Hunter, N. (2006). Crises in social reproduction in a developmental state: Home-based care in KwaZulu-Natal. Centre for Civil Society Colloquium on the Economy. Society and Nature, 1-18.

Lehmann, U. (2008). Strengthening human resources for primary health care. In P. Barron \& J. Roma-Reardon (Eds.), South African health review 2008 (163-178). Durban: Health System Trust.

Lehmann, U., \& Matwa, P. (2008). Exploring the concept of power in the implementation of South Africa's new community health worker policies: A case study from a rural district. EQUINET Discussion Paper Series 63. Harare: EQUINET, CHP.

Lehmann, U., Matwa, P., Schneider, H., \& Colvin, C. (2009). A map of community care giver programme practices in provincial health departments. Report to the Health Systems Subcommittee of the South National Aids Council (SANAC). Cape Town: UWC/IDEU.

Lehmann, U., \& Sanders, D. (2007). Community health workers what do we know about them? The state of the evidence on programmes, activities, costs and impact on health outcomes of using community health workers.

Evidence and Information for Policy, Department of Human Resources for Health. Geneva: WHO.

Lewin, S.A., Dick, J., Pond, P., Zwarenstein, M., Aja, G., van Wyk, B., et al. (2005). Lay health workers in primary and community health care. Cochrane Database Systematic Review, 25(1), Doo4015.

\section{https://repository.uwc.ac.za/}


Maher, D. (2003). The role of the community in the control of tuberculosis. Tuberculosis, 83, 177-182.

Marais, H. (2005). Buckling: The impact of HIV in South Africa. Pretoria: Centre for the Study of AIDS, University of Pretoria.

Marchal, B., Cavall, A., \& Kegels, G. (2009). Global health actors claim to support health system strengthening is this reality or rhetoric? PLoS Medicine, 6(4), e1000059.

Marq, J., Theobald, S., Dick, J., \& Dembele, M. (2003). An exploration of the concept of directly observed treatment treatment (DOT) for tuberculosis patients: From a uniform to a customised approach. International Journal of Tuberculosis and Lung Disease, 7, 1-7.

Nguyen, V.K. (2007). Adherence as therapeutic citizenship: Impact of the history of access to antiretroviral drugs on adherence to treatment. AIDS, 21(Suppl. 5), S31-S35.

Ogden, J., Esim, S., \& Grown, C. (2006). Expanding the care continuum for HIV/AIDS: Bringing carers into focus. Health Policy and Planning, 21(5), 334-342.

Porter, J.D.H., \& Ogden, J.A. (1997). Ethics of directly observed therapy for the control of infectious diseases. Bulletin de I'Institut Pasteur, 95, 117-127.

Rohde, J., Cousens, S., Chopra, M., Tangcharoensathien,V., Black, R., Bhutta, Z.A., et al. (2008). 30 years after Alma Ata: Has primary health care worked in countries? Lancet, 372, 950-961.

Rohleder, P., \& Swartz, L. (2005). 'What I've noticed what they need is the stats': Lay HIV counsellors' reports of working in a task-orientated health care system. AIDS Care, 17(3), 397-406.

Samson, M. (2008). Organising health home and community based workers in South Africa. Consultancy Report. Johannesburg: Naledi.

Schneider, H., \& Coetzee, D. (2003). Strengthening the health system and ensuring equity in the wide-scale implementation of an antiretroviral therapy programme in South Africa (editorial). South African Medical Journal, 93(10), 772-773.

Schneider, H., Hlophe, H., \& van Rensburg, D. (2008). Community health workers and the response to HIV/AIDS in South Africa: Tensions and prospects. Health Policy and Planning, 23(3), 179-187.

Standing, H., \& Chowdhury, M. (2008). Producing effective knowledge agents in a pluralistic environment: What future for community health workers? Social Science and Medicine, 66, 2096-2017.

Uys, L. (2002). The practice of community caregivers in a home-based HIV/AIDS project in South Africa. Journal of Clinical Nursing, 11, 99 -108.

\section{https://repository.uwc.ac.za/}


Volmink, J., \& Garner, P. (2007). Directly observed therapy for treating tuberculosis. Cochrane Database of Systematic Reviews, (4), CDoo3343.

Walt, G. (Ed.). (1990). Community health workers in national programmes: Just another pair of hands?

Philadelphia: Open University Press.

WHO (2002). Community home-based care in resource-limited settings: A framework for action. Geneva: Author.

WHO Maximizing Positive Synergies Collaborative Group (2009). An assessment of interactions between global

health initiatives and country health systems. The Lancet, 373(9681), 21372169.

WHO/UNAIDS/PEPFAR (2008). Task shifting: Global recommendations and guidelines. Geneva: WHO. Retrieved

September 4, 2009, from http://www.who.int/healthsystems/task_shifting/en/index.html Wilkinson, D., Davies, G.R., \& Connolly, C. (1996). Directly observed therapy for tuberculosis in rural

South Africa, 1991 through 1994. American Journal of Public Health, 86, 10941097. 